Article

\title{
Contagion of the Subprime Financial Crisis on Frontier Stock Markets: A Copula Analysis
}

\author{
Wahbeeah Mohti ${ }^{1}$, Andreia Dionísio ${ }^{1,2}$ (D), Paulo Ferreira ${ }^{2,3}$ (D) and Isabel Vieira ${ }^{2,4, *}$ \\ 1 Department of Management, Universidade de Évora, 7000-812 Évora, Portugal; \\ beeah_awan@yahoo.com (W.M.); andreia@uevora.pt (A.D.) \\ 2 CEFAGE, Universidade de Évora, 7000-812 Évora, Portugal; pferreira@ipportalegre.pt \\ 3 VALORIZA-Research Center for Endogenous Resource Valorization, 7300-110 Portalegre, Portugal \\ 4 Department of Economics, Universidade de Évora, 7000-812 Évora, Portugal \\ * Correspondence: impvv@uevora; Tel.: +351-266740800
}

Received: 13 December 2018; Accepted: 10 February 2019; Published: 26 February 2019

\begin{abstract}
This study assesses contagion from the USA subprime financial crisis on a large set of frontier stock markets. Copula models were used to investigate the structure of dependence between frontier markets and the USA, before and after the occurrence of the crisis. Statistically significant evidence of contagion could only be found in the European region, with the markets of Croatia and Romania being affected. The remaining European markets in our sample and the others, located in America, Middle East, Africa, and Asia, appear to have been isolated from the subprime crisis impact. These results are useful for international investors interested in enlarging the geographical diversification of their portfolios, but also for the considered countries' policymakers who should attempt to improve the attractiveness of stock markets for domestic and foreign investors while simultaneously attempting to maintain their relative level of insulation against future foreign crises.
\end{abstract}

Keywords: copula models; financial contagion; financial crises; frontier markets

JEL Classification: F30; G01; G15

\section{Introduction}

In this study, we used copulas to investigate financial contagion from the USA subprime crisis to frontier markets. Academic interest in financial contagion emerged in the last decade of the 20th century, with the advance of globalization and the increasing interconnectedness of financial institutions across borders. Nevertheless, financial crises have largely preceded such interest. In fact, with the exception of the first two decades following the end of the Second World War, crises have been rather frequent events. Relevant examples since 1980 are the 1987 USA stock market crash, the 1994 Mexican crisis, the 1997 Asian crisis, the 1998 Russian crisis, the 2007/08 USA subprime crisis, and the 2011 sovereign debt crisis in the European Union.

The subprime financial crisis has been considered the most severe event in recent history, only comparable to the stock market crash of 1929. The common attribute of all these episodes is that they caused dramatic drops in asset prices and increases in market volatility, firstly in the country of origin and subsequently in a number of other financial markets, with different sizes and structures. Such spreading of crises' effects led researchers to investigate whether cross-market co-movements provide evidence of contagion.

Although there is no consensus in the literature concerning the definition of financial contagion, one of the most often adopted concepts (which we also follow) was proposed by Forbes and Rigobon (2002, pp. 2223, 2224), according to whom contagion is a "significant increase in the cross market 
linkages after a shock to one country (or group of countries)." In early studies, a typical procedure to assess contagion was to compute Pearson's linear correlation coefficients in order to gauge the strength of the links between markets before and after a crisis. Post-shock significant increases in such coefficients were interpreted as evidence of contagion. However, as stated inter alia by Forbes and Rigobon (2002), Pearson's correlation coefficients are conditional on market volatility, and therefore, their increase in turbulent periods does not necessarily indicate that contagion existed. In the presence of heteroscedasticity, for instance, linear correlation between markets may increase after a crisis, even when there is no increment in the underlying links, thus leading to biased conclusions. The authors proposed a technique to correct for heteroscedasticity and found no evidence of contagion for the crises of the second half of the 1990s. When linear correlation is high before a crisis, subsequent increases may reflect the prolongation of strong cross-market links, for which the authors proposed the designation of interdependence.

Pearson's correlation coefficients provide information on the strength of links between two (jointly) normally distributed random variables. If this is not the case, such coefficients are not reliable (Embrechts et al. 2003). Furthermore, assessments of contagion based on Pearson's correlation coefficients do not detect contagion if dependence is non-linear.

The many published evaluations of financial contagion vary in terms of methodological approach and geographical focus (for a review of early studies, see Horta et al. 2010). Relatively recent assessments have focused on the 2007/08 financial crisis with origin in the USA and on its contagion to the markets of various countries: the so-called BRICs (Brazil, Russia, India and China) (Mensi et al. 2016), countries in Latin America (Romero-Meza et al. 2015), Middle East and North Africa (Neaime 2012), Asia (Khan and Park 2009), or Central and Eastern Europe (Demian 2011).

Fry et al. (2010) used co-skewness based tests to detect contagion channels that could not be identified in correlation assessments. Their study focused on the real estate and equity markets and on contagion originating in the 1997-1998 Hong Kong and the 2007-2008 USA crises. Boubaker et al. (2016) used co-integration and Granger causality tests to examine contagion risk associated to the subprime crisis, finding evidence of contagion in both developed (Canada, France, Germany, Japan, UK), and emerging markets (Brazil, Russia, China, Malaysia and Singapore). Aloui et al. (2011) used copulas to assess the BRIC countries, concluding that there was strong evidence of time varying dependence between each market and the USA. The results from the two latter studies contrast with those of Dimitriou et al. (2013) who, applying the multivariate fractionally integrated asymmetric power ARCH dynamic conditional correlation methodology to investigate the BRICs' and South Africa's markets, concluded that the assessed markets did not display evidence of contagion in the early phases of the USA crisis. Linear correlation between these countries' markets and the USA increased from early 2009 onwards, depicting larger dependence in bullish than in bearish periods; however, the authors concluded that there was no evidence of contagion.

A study of 11 crisis episodes developed by Dewandaru et al. (2015) using wavelet decomposition suggests that impacts vary with the level of financial integration and that the Asian and the Russian crises had the most influential contagion effects.

Considering European markets, Horta et al. (2014) investigated contagion effects of both the USA financial crisis and the European sovereign debt crisis in the stock markets of Belgium, France, Greece, Japan, the Netherlands, Portugal and the UK. The authors first assessed these markets' efficiency and subsequently used copula models to investigate their dependence structures. The results suggested that there was significant contagion from both crises, with the former displaying more prominent effects.

Evidence of contagion is weaker in frontier markets and in some non-core Asian markets. Kiviaho et al. (2014) developed a wavelet coherency analysis of frontier markets showing that the co-movements with the USA are weaker for Central and South Eastern European countries than for those in the Baltic region (the Slovakian market displays low dependence, whereas that of Lithuania is more dependent) and have increased with the financial crisis. Using VAR EGARCH dynamic conditional correlation response functions, Amin and Orlowski (2014) showed that the stock markets 
in Pakistan, Bangladesh, and Sri Lanka were decoupled from their developed counterparties during periods of financial normality and became more subject to their influence (via a dominant regional market such as that of India) during a crisis. Daugherty and Jithendranathan (2015) applied variance ratios, conditional correlation and transfer entropy to investigate integration between frontier markets and the USA. The results revealed that the European markets received more information flows from USA markets and that integration increased with the financial crisis but not with the European debt crisis.

Copula models have been used to examine contagion from the USA subprime crisis into developed countries, but have not been adopted in assessments of frontier markets. In this study, we developed such an analysis and produced evidence that adds to the literature on financial contagion. The motivation for our choice of methodology was the fact that copula models are flexible and adequate to investigate links between non-normally distributed variables. Furthermore, and according to $\mathrm{Hu}$ (2006), although it is not possible to assess how two markets are related in volatile periods using simple correlation coefficients, as they only measure the level of dependence, with copula models it is possible to study both the level and the structure of dependence.

Various assessments of contagion have used copulas-see for instance Patton (2006); Xu and Li (2009); Hu (2006, 2010); Nikoloulopoulos et al. (2012); Horta et al. (2010); Horta et al. (2014). High dimensional copulas are difficult to handle and limited in number, in contrast to parametric bivariate copulas, which are available in large numbers (Aas et al. 2009). We used the latter models to investigate dependence structures between the USA and frontier markets and to assess the existence of contagion from the USA subprime financial crisis. Following Trivedi and Zimmer (2005), who defended that it is more adequate to consider several copulas in order to select the best fit according to the specific structure of the data, we considered eight copulas: t-Student, Clayton, Gumbel, Frank, Gaussian, Clayton-Gumbel (CG), Gumbel-Survival-Gumbel (GSG), and Clayton-Gumbel-Frank (CGF). We assessed evidence of contagion using the Kendall's $\tau$ and the Spearman's $\rho$ as rank correlation measures. The empirical analysis suggests that, of the 18 analyzed countries, only Croatia and Romania exhibited significant evidence of contagion. These results are informative for investors interested in the potential benefits of international portfolio diversification into frontier markets.

\section{Materials and Methods}

Copula models were used to investigate contagion effects of the USA subprime financial crisis into frontier markets. The following 18 frontier markets, classified by Morgan and Stanley International Capital International (MSCI) ${ }^{1}$, were considered (by region):

America and Europe-Argentina, Croatia, Estonia, Romania, Slovenia;

Africa-Kenya, Mauritius, Morocco, Nigeria and Tunisia;

Middle East-Bahrain, Jordan, Kuwait, Lebanon, Oman;

Asia-Pakistan, ${ }^{2}$ Sri Lanka, Vietnam.

The daily closing prices for each country's stock market representative index were collected from DataStream. The time line used in the study was:

Calm period: from 4 January 2005 to 31 July 2007 (671 data points);

1 The main providers of frontier markets' indices are MSCI, FTSE Russell, a unit of the London Stock Exchange Group, and Standard \& Poor's. The list of criteria used by the first two (mainly related to restrictions on foreign ownership of listed stocks and minimum liquidity requirements), and thus the list of markets they consider as frontier are very similar. In the Standard and Poor's classification, macroeconomic indicators play a more prominent role and their list is usually larger than those of MSCI's and FTSE's. We followed the choice of most financial researchers investigating frontier markets and chose MSCI as the source of our data. Details on their classification can be found at https:/ / www.msci.com/market-classification.

2 Pakistan was reclassified as an emerging market in May 2017. We considered it as a frontier market because it was how the country was classified at the time of data collection (before May 2017). 
Crisis period: from 1 August 2007 to 7 December 2009 (614 data points).

We followed Horta (2013) and Horta et al. (2014) in assuming that the bust of the mortgage bubble, which marked the beginning of the USA financial crisis (see also Gallegati 2012), took place on 1 August 2007. Fry et al. (2010) also concurred in admitting that the subprime financial crisis started in the mid of 2007. However, several authors used different starting dates for the subprime financial crisis (Da Silva et al. 2016). Guedes et al. (2017) considered the whole year of 2008 as a crisis period.

Nelsen $(2007$, p. 1) defined copulas as " ... functions that join or 'couple' multivariate distribution functions to their one-dimensional marginal distribution functions". Rodriguez (2007, pp. 407-8) pointed out the main reasons why copulas are especially adequate to the analysis of financial contagion: "First, copulas are invariant to strictly increasing transformation of the random variables. Second, widely used measures of concordance ${ }^{3}$ between random variables, like Kendall's tau and Spearman's rho, are properties of copula. Third, and of the greatest importance in the study of financial contagion, asymptotic tail dependence is also a property of the copula."

In the financial literature, researchers such as Bouyé et al. (2000) and Embrechts et al. (2002, 2003) have provided broad guidelines for the application of copulas and many have used them in their studies (see Li 2000; Longin and Solnik 2001; Mashal and Zeevi 2002, among others). A variety of copulas have been proposed, including Gaussian and t-Student (e.g., Lee 1983) and copulas from the Archimedean family (such as Clayton (1978), Gumbel (1960), and Frank (1979). According to Trivedi and Zimmer (2005), Gaussian and t-Student copulas are appropriate for the analysis of symmetric dependence structures, but allow only simple estimations. The Clayton and Gumbel copulas cannot account for negative dependence and exhibit left and right tail dependence, respectively. The Frank copula is more suitable for cases of weak tail dependence. ${ }^{4}$

Kole et al. (2007) applied Gaussian, t-Student and Gumbel copulas in a study of portfolio risk management of stocks, bonds and real estate and concluded that the t-Student copula is more appropriate in the context of risk management. Numerous empirical studies used individual or pure copulas to study dependence structures. However, this strategy changed with Hu's (2006) defence of mixed copulas as more adequate to such end. The mixture of Gumbel and Survival Gumbel, Gumbel and Clayton are both suitable to assess dependence in cases where symmetry is nearly ideal, or where different forms of asymmetry and independence exist.

The most relevant aspect of the theory of copulas is the Sklar theorem (Sklar 1959), stating that any $\mathrm{n}$-dimensional distribution function $f$ with univariate marginal distribution functions $f_{1} \ldots f_{\mathrm{n}}$ can be written as:

$$
f\left(y_{1}, \ldots \ldots, y_{n}\right)=c\left(f_{1}\left(y_{1}\right), \ldots \ldots, f_{n}\left(y_{n}\right) ; \theta\right)
$$

where, $y=y_{1}, \ldots \ldots \ldots, y_{n}$ are vectors of random variables, $c$ is the copula and $\theta$ represents the dependence vector of the copula function. If, $f_{i}\left(y_{i}\right)=u_{t}$ with $u_{i} \sim$ unif $[0,1]$, than Equation (1) is written as:

$$
c\left(u_{1}, \ldots \ldots, \ldots, u_{n} ; \theta\right)=f\left(f_{1}^{-1}\left(u_{1}\right) \ldots \ldots \ldots, f_{n}^{-1}\left(u_{n}\right)\right)
$$

with $f_{i}^{-1}$ representing the inverse distribution function of $y_{i}$ (e.g., see Nelsen 2007).

Although it is possible to analyze the dependence structure between variables solely with copulas, it is more common to recur to dependence measures calculated from the copulas to summarize complicated dependence structures in a single number. We use rank correlation and asymptotic tail dependence to measure the dependence structure between variables (Schmidt 2007). Rank correlation coefficients such as Kendall's $\tau$ and Spearman's $\rho$ are directly obtained from an estimated copula

3 Two random variables $\mathrm{x}$ and $\mathrm{y}$ are concordant, if the large and small values of $\mathrm{x}$ are associated with the large and small values of $y$ (Nelsen 2007).

4 For more technical details on copulas, see e.g., Trivedi and Zimmer (2005), or Nelsen (2007). 
(Nelsen 2007). These coefficients allow comparisons of global dependence when more than one copula is considered because distinct copulas' dependence parameters are non-comparable.

$$
\begin{gathered}
\text { Kendall } \tau\left(y_{1}, y_{2}\right)=1-4 \int_{0}^{1} \int_{0}^{1} \frac{\alpha c\left(u_{1}, u_{2}\right)}{\alpha u_{1}} \frac{\alpha c\left(u_{1}, u_{2}\right)}{\alpha u_{12}} n u_{1} n u_{2} \\
\text { Spearman } \rho\left(y_{1}, y_{2}\right)=12 \int_{0}^{1} \int_{0}^{1}\left(c\left(u_{1}, u_{2}\right)-u_{1} u_{2} n u_{1} n u_{2}\right)
\end{gathered}
$$

The values of the rank correlation coefficients vary between -1 and +1 . Upper $\left(\lambda_{U}\right)$ and lower $\left(\lambda_{L}\right)$ asymptotic tail dependence coefficients were also directly obtained from the copulas and were used as measures of dependence. Copulas present different asymptotic tail dependence coefficients: the Clayton and Gumbel copulas provide lower and upper tail coefficients, respectively; the t-Student copulas display both upper and lower tail coefficients; the remaining cases, such as the Gaussian and Frank copulas, do not display tail coefficients.

According to Schmidt (2007), $\lambda_{U}$ and $\lambda_{L}$ are defined as:

$$
\begin{aligned}
& \lambda_{u}=\lim _{q \rightarrow 0} P\left(y_{2}>f_{2}^{-1}(q) \mid y_{1}>f_{1}^{-1}(q)\right) \\
& \lambda_{l}=\lim _{q \rightarrow 0} P\left(y_{2} \leq f_{2}^{-1}(q) \mid y_{1} \leq f_{1}^{-1}(q)\right)
\end{aligned}
$$

We estimated the copulas using the method proposed by McLeish and Small (1988), which was based on inference functions for margins (IFM) (see Horta et al. 2010). This method has the advantage of allowing the evaluation of marginal distributions before the estimation of the copulas, thus avoiding the possibility of estimating low quality copulas.

The process adopted to assess financial contagion between the USA and the frontier markets is the following:

(1) We calculated the returns of each series, and removed autocorrelation and heteroscedasticity applying an ARMA-GARCH model. The standardized residuals were extracted and labeled as filtered returns. ${ }^{5}$

(2) The filtered returns were divided into two periods-one of calm and one of crisis. The maximum likelihood value was used to evaluate the parametric distribution functions (Gaussian, t-Student, logistic and Gumbel) estimated for both calm and crisis periods. We used the Akaike information criterion (AIC) to select the most appropriate parametric distribution function for each series.

(3) Five pure and three mixed copulas were considered for each series and the most appropriate one was selected. The pure copulas were: Clayton, t-Student, Gumbel, Frank, and Gaussian. Mixed copulas included: Clayton-Gumbel (CG), Gumbel-Survival-Gumbel (GSG) and Clayton-Gumbel-Frank (CGF). The marginal distributions selected in the second step were used to estimate the copulas and maximum likelihood and AIC values were the basis for the selection of the most appropriate model.

(4) After the copulas' estimation, the $\lambda_{U}, \lambda_{L}, \tau$ and $\rho$ coefficients were used to assess the degree of dependence between the variables.

(5) Lastly, we employed the bootstrap method proposed by Trivedi and Zimmer (2005) to estimate the copulas' variance-covariance matrix $\mathrm{V}$ of parameters and other indicators.

The bootstrap method was also performed in five steps:

5 Henceforth, the word "returns" means filtered returns. 
(a) We used the IFM method to obtain the marginal distributions of both the vector of parameters $\left(\hat{\beta}_{1}\right.$ and $\hat{\beta}_{2}$ ) and the vector of copulas' dependence parameters $\hat{\theta}$. The global vector of the parameters was $\hat{\Omega}=\left(\hat{\beta}_{1}, \hat{\beta}_{2}, \hat{\theta}\right)^{\prime}$.

(b) From the original data, we drew a random sample with replacement.

(c) On the random sample, we again used the IFM method to re-evaluate $\beta_{1}, \beta_{2}$ and $\theta$ and stored their values.

(d) We repeated steps (b) and (c) R times and used the estimated parameters, $\hat{\beta}_{1}(r), \hat{\beta}_{2}(r)$ and $\hat{\theta}(r)$ for the Rth re-estimation. The global vector of parameters was $\hat{\Omega}(r)=\left(\hat{\beta}_{1}(r), \hat{\beta}_{2}(r), \hat{\theta}(r)\right)^{\prime}$.

(e) We obtained the standard errors of the parameters by taking the squared roots of the elements in the main matrix V. $\hat{V}=R^{-1} \sum_{r=1}^{R}(\hat{\Omega}(r)-\hat{\Omega})(\hat{\Omega}(r)-\hat{\Omega})^{\prime}$.

To test for the existence of contagion, we used both the Spearman's $\rho$ and Kendall's $\tau$. The same bootstrap technique was applied to compute the standard errors of the dependence parameters. This test investigated the existence of contagion by analyzing the dependence between the USA and each frontier market to check whether dependence increases from the calm to the crisis period.

The null hypotheses of non-contagion were defined as:

$$
\begin{aligned}
& H_{0}: \Delta \tau(i)=\tau_{\text {crisis }}(i)-\tau_{\text {pre-crisis }}(i) \leq 0 \\
& H_{1}: \Delta \tau(i)=\tau_{\text {crisis }}(i)-\tau_{\text {pre-crisis }}(i)>0 \\
& H_{0}: \Delta \rho(i)=\rho_{\text {crisis }}(i)-\rho_{\text {pre-crisis }}(i) \leq 0 \\
& H_{1}: \Delta \rho(i)=\rho_{\text {crisis }}(i)-\rho_{\text {pre-crisis }}(i)>0
\end{aligned}
$$

with $i$ designating the pair US/Frontier market $i$.

$\tau_{\text {crisis }}(i)$ and $\tau_{\text {pre-crisis }}(i)$, and $\rho_{\text {crisis }}(i)$ and $\rho_{\text {pre-crisis }}(i)$, designating global dependence between the USA and each frontier stock market. $\Delta \tau(i)$ and $\Delta \rho(i)$ indicate variation in global dependence between the USA and frontier market (i) from the calm to the crisis period. Rejection of the null hypothesis indicates the existence of contagion.

\section{Results}

We started by computing the series of returns for each market and then removing autocorrelation and heteroscedasticity with an ARMA-GARCH model. The standardized residuals extracted were the filtered returns (step 1). Subsequently, marginal distributions were estimated with maximum likelihood from the set of Gaussian, Gumbel, t-Student, and logistic copulas, and AIC values were used to select the most appropriate (step 2). For most of the indices, the t-Student and logistic distributions were selected, indicating that the series of returns display heavy tails (see Table 1). The Gaussian copula was solely selected for the Vietnamese stock market, confirming that our choice of methodology was adequate.

In step 3, eight copulas were estimated for each pair composed by a frontier market and the USA and, again, the most appropriate model was selected using the AIC. The values of the dependence, rank correlations $(\tau, \rho)$ and tail dependence parameters $\left(\lambda_{u}\right.$ and $\left.\lambda_{l}\right)$ for each selected copula, and for the calm and the crisis periods, are displayed by region in Tables $2-5$.

Focusing on the calm period, there is evidence of symmetry in co-movements for the majority of the analyzed pairs of markets. Pure copulas, such as the Gaussian and Frank models, were selected for USA/Croatia, USA/Slovenia, USA/Jordan, USA/Kuwait, USA/Oman USA/Sri Lanka, USA/Mauritius, USA/Morocco, USA/Nigeria and USA/Tunisia. Both copulas provided values of zero for the asymptotic tail coefficients.

The Gumbel copula was chosen for USA/Romania, USA/Kenya, USA/Bahrain, USA/Lebanon and USA/Pakistan, reflecting the asymmetry in co-movements of these series. The Clayton copula was selected solely for the pair USA/Estonia, indicating that the link between the two countries' markets was more prominent in the period of sharp decline. 
The mixed copula Gumbel-Survival-Gumbel (GSG) was selected for USA/Argentina, indicating that these returns have an asymmetric distribution. The extreme dependence between the two series was gauged by the $\lambda_{U}$ (upper right tail) and $\lambda_{\mathrm{L}}$ (lower left tail) coefficients. These values indicated that the probability of simultaneous co-movements between the USA and Argentina was more pronounced during booms $\left(\lambda_{U}=0.2767\right)$ than during busts $\left(\lambda_{L}=0.0598\right)$. The first parameter $\theta_{1}$ and the weight $w_{1}$ belong to the Gumbel part of the mixed copula, and $\theta_{2}$ and weight $w_{2}$ to the survival Gumbel's part.

Table 1. Selected Marginal Distributions for Frontier Markets.

\begin{tabular}{cccccc}
\hline America and Europe & Argentina & Croatia & Estonia & Romania & Slovenia \\
\hline Calm Period & t-Student & t-Student & t-Student & t-Student & t-Student \\
\hline AIC & -873.574 & -909.431 & -834.21 & -942.442 & -738.872 \\
\hline Crisis Period & logistic & t-Student & t-Student & logistic & logistic \\
\hline AIC & -881.197 & -880.042 & -852.455 & -912.316 & -900.513 \\
\hline Africa & Kenya & Mauritius & Morocco & Nigeria & Tunisia \\
\hline Calm Period & Logistic & t-Student & t-Student & Logistic & logistic \\
\hline AIC & -910.287 & -882.319 & -939.81 & -863.441 & -882.354 \\
\hline Crisis Period & Logistic & Logistic & Logistic & Logistic & t-Student \\
\hline AIC & -906.751 & -892.378 & -888.617 & -888.698 & -868.285 \\
\hline Middle East & Bahrain & Jordan & Kuwait & Lebanon & Oman \\
\hline Calm Period & t-Student & t-Student & Logistic & t-Student & t-Student \\
\hline AIC & -910.429 & -915.494 & -933.674 & -773.791 & -874.433 \\
\hline Crisis Period & t-Student & Logistic & t-Student & t-Student & Logistic \\
\hline AIC & -874.598 & -888.34 & -852.198 & -706.412 & -876.142 \\
\hline Asia & Pakistan & Sri Lanka & Vietnam & - & - \\
\hline Calm Period & Logistic & t-Student & logistic & - & - \\
\hline AIC & -971.585 & -922.345 & -908.606 & - & - \\
\hline Crisis Period & Logistic & t-Student & Gaussian & - & - \\
\hline AIC & -879.494 & -849.888 & -885.919 & - & - \\
\hline A & Akaik & & - & - \\
\hline
\end{tabular}

Note: Akaike information criterion (AIC) values for the non-selected copula models are not shown but are available upon request.

Table 2. Selected Copulas-USA/America and USA/Europe.

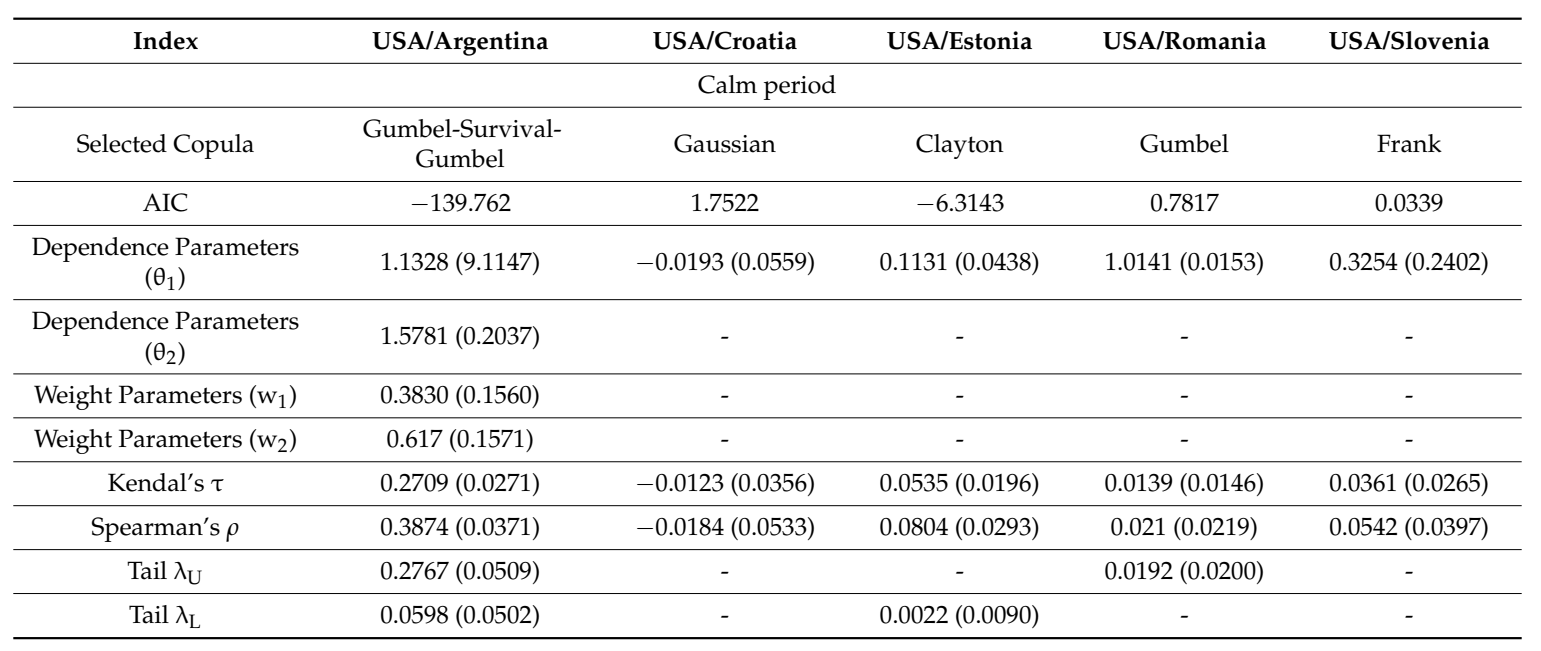


Table 2. Cont.

\begin{tabular}{|c|c|c|c|c|c|}
\hline Index & USA/Argentina & USA/Croatia & USA/Estonia & USA/Romania & USA/Slovenia \\
\hline \multicolumn{6}{|c|}{ Crisis period } \\
\hline Selected Copula & Clayton-Gumbel-Frank & Gaussian & Clayton & Gaussian & Frank \\
\hline $\begin{array}{l}\text { Dependence Parameters } \\
\qquad\left(\theta_{1}\right)\end{array}$ & $0.4927(5.9462)$ & $0.2244(0.0361)$ & $0.1028(0.0420)$ & $0.2258(0.0384)$ & $0.6145(0.2411)$ \\
\hline $\begin{array}{c}\text { Dependence Parameters } \\
\left(\theta_{3}\right)\end{array}$ & $12.1250(17.193)$ & - & - & - & - \\
\hline Weight Parameters $\left(\mathrm{w}_{1}\right)$ & $0.4379(0.1493)$ & - & - & - & - \\
\hline Weight Parameters $\left(\mathrm{w}_{2}\right)$ & $0.2865(0.1703)$ & - & - & - & - \\
\hline Tail $\lambda_{\mathrm{U}}$ & $0.141(0.0955)$ & - & - & - & - \\
\hline Tail $\lambda_{\mathrm{L}}$ & $0.1072(0.0640)$ & - & $0.0012(0.0072)$ & - & - \\
\hline
\end{tabular}

Note: Standard errors in parenthesis.

Table 3. Selected Copulas-US/Africa.

\begin{tabular}{|c|c|c|c|c|c|}
\hline Index & USA/Kenya & USA/Mauritius & USA/Morocco & USA/Nigeria & USA/Tunisia \\
\hline Selected Copula & Gumbel & Frank & Frank & Gaussian & Gaussian \\
\hline Dependence Parameters $\left(\theta_{1}\right)$ & $1.0365(0.0222)$ & $0.6027(0.2321)$ & $-0.041(0.2357)$ & $-0.0028(0.0364)$ & $\begin{array}{c}-0.0183 \\
(0.0558)\end{array}$ \\
\hline Spearman's $\rho$ & $0.0529(0.0307)$ & $0.1(0.0380)$ & $-0.0068(0.0392)$ & $-0.0027(0.0350)$ & $\begin{array}{l}-0.0174 \\
(0.0533)\end{array}$ \\
\hline Tail $\lambda_{U}$ & $0.0482(0.0278)$ & - & - & - & - \\
\hline Tail $\lambda_{\mathrm{L}}$ & - & - & - & - & - \\
\hline Dependence Parameters $\left(\theta_{1}\right)$ & $-0.1158(0.0278)$ & $1.028(0.0193)$ & $1.014(0.0161)$ & $-0.0431(0.0958)$ & $0.0369(0.0422)$ \\
\hline Kendal's $\tau$ & $-0.0129(0.0133)$ & $0.0272(0.0180)$ & $0.0138(0.0154)$ & $-0.0274(0.0611)$ & $0.0235(0.0269)$ \\
\hline Spearman's $\rho$ & $-0.0193(0.0200)$ & $0.041(0.0270)$ & $0.0209(0.0231)$ & $-0.0411(0.0915)$ & $0.0353(0.0403)$ \\
\hline Tail $\lambda_{U}$ & - & $0.0374(0.0245)$ & $0.0191(0.0210)$ & - & - \\
\hline Tail $\lambda_{\mathrm{L}}$ & $0(0.000)$ & - & - & - & - \\
\hline
\end{tabular}

Note: Standard errors in parenthesis.

Table 4. Selected Copulas-USA/Middle East.

\begin{tabular}{cccccc}
\hline Index & USA/Bahrain & USA/Jordan & USA/Kuwait & USA/Lebanon & USA/Oman \\
\hline & Gumbel & Frank & Frank & Gumbel & Gaussian \\
\hline Selected Copula & -2.3309 & 1.9928 & 1.7384 & 0.9466 & -0.9323 \\
\hline AIC & $1.0424(0.0234)$ & $0.0195(0.2135)$ & $0.1233(0.2507)$ & $1.0208(0.0191)$ & $0.0664(0.0356)$ \\
\hline $\begin{array}{c}\text { Dependence } \\
\text { Parameters }\left(\theta_{1}\right)\end{array}$ & $0.0407(0.0214)$ & $0.0022(0.0237)$ & $0.0137(0.0277)$ & $0.0204(0.0180)$ & $0.0423(0.0227)$ \\
\hline Kendal $\tau$ & $0.0611(0.0320)$ & $0.0033(0.0355)$ & $0.0205(0.0416)$ & $0.0307(0.0271)$ & $0.0634(0.0340)$ \\
\hline Spearman $\rho$ & $0.0556(0.0288)$ & - & - & $0.0281(0.0246)$ & - \\
\hline Tail $\lambda_{\mathrm{U}}$ & - & - & - & - \\
\hline Tail $\lambda_{\mathrm{L}}$ & & & & & -
\end{tabular}


Table 4. Cont.

\begin{tabular}{cccccc}
\hline Index & USA/Bahrain & USA/Jordan & USA/Kuwait & USA/Lebanon & USA/Oman \\
\hline \multicolumn{5}{c}{ Crisis period } \\
\hline Selected Copula & Frank & Clayton & Frank & Clayton & Clayton \\
\hline AIC & 1.4757 & 1.2378 & 1.7977 & -0.6647 & 0.9685 \\
\hline $\begin{array}{c}\text { Dependence } \\
\text { Parameters }\left(\theta_{1}\right)\end{array}$ & $0.1775(0.2554)$ & $0.0316(0.0327)$ & $-0.1158(0.3465)$ & $0.0695(0.0417)$ & $0.0303(0.0270)$ \\
\hline Kendal $\tau$ & $0.0197(0.0282)$ & $0.0156(0.0155)$ & $-0.0129(0.0384)$ & $0.0336(0.0193)$ & $0.0149(0.0129)$ \\
\hline Spearman $\rho$ & $0.0296(0.0424)$ & $0.0234(0.0234)$ & $-0.0193(0.0575)$ & $0.0505(0.0289)$ & $0.0224(0.0194)$ \\
\hline Tail $\lambda_{\mathrm{U}}$ & - & - & - & - & - \\
\hline Tail $\lambda_{\mathrm{L}}$ & - & $0.000(0.001)$ & - & $0.000(0.004)$ & $0.000(0.000)$ \\
\hline \multicolumn{7}{c}{ Note: Standard errors in parenthesis. }
\end{tabular}

Table 5. Selected Copulas-USA/Asia.

\begin{tabular}{cccc}
\hline Index & USA/Pakistan & USA/Sri Lanka & USA/Vietnam \\
\hline Selected Copula & Calm period & & \\
\hline AIC & Gumbel & Frank & Clayton-Gumbel \\
\hline Dependence Parameters $\left(\theta_{1}\right)$ & -0.8617 & 1.9415 & 1.8099 \\
\hline Dependence Parameters $\left(\theta_{2}\right)$ & $1.0387(0.0237)$ & $-0.0563(0.2582)$ & $0.0000(0.1679)$ \\
\hline Weight Parameters $\left(\mathrm{w}_{1}\right)$ & - & - & $19.5076(15.524)$ \\
\hline Weight Parameters $\left(\mathrm{w}_{2}\right)$ & - & - & $0.9789(0.1108)$ \\
\hline Kendal $\tau$ & - & - & $0.0211(0.1108)$ \\
\hline Spearman $\rho$ & $0.0373(0.0218)$ & $-0.0063(0.0286)$ & $0.02(0.0162)$ \\
\hline Tail $\lambda_{\mathrm{U}}$ & $0.056(0.0326)$ & $-0.0094(0.0429)$ & $0.021(0.0215)$ \\
\hline Tail $\lambda_{\mathrm{L}}$ & $0.051(0.0294)$ & - & $0.0204(0.0138)$ \\
\hline Selected Copula & & - & $0(0.0048)$ \\
\hline AIC & Gaussian & Grisis period & \\
\hline Kendal $\tau$ & 1.1473 & 1.2567 & Frank \\
\hline Spearman $\rho$ & $0.0363(0.0343)$ & $1.0153(0.0162)$ & $-0.1499(0.2747)$ \\
\hline Tail $\lambda_{\mathrm{U}}$ & $0.0231(0.0219)$ & $0.015(0.0154)$ & $-0.0167(0.0303)$ \\
\hline Dependence Parameters $\left(\theta_{1}\right)$ & $0.0347(0.0328)$ & $0.0227(0.0232)$ & $-0.025(0.0455)$ \\
\hline & - & $0.0207(0.0211)$ & - \\
\hline
\end{tabular}

Note: Standard errors in parenthesis.

The best-fit copula for the pair USA/Vietnam was the Clayton-Gumbel, indicating that asymmetric tail dependence is more significant on the right side.

Concerning the value of the Kendal's $\tau$, all frontier markets displayed positive rank correlation values with the USA market (highest for Argentina with 0.27), except Croatia, Morocco, Nigeria, and Sri Lanka, which displayed negative rank correlation values, suggesting that each of these markets and the USA moved in opposite directions.

Focusing on the subprime financial crisis period now, the symmetry in co-movements is illustrated by the choice of the Gaussian and Frank copulas for the majority of assessed pairs: USA/Croatia, USA/Romania, USA/Slovenia, USA/Mauritius, USA/Morocco, USA/Nigeria, USA/Tunisia, USA/Bahrain, USA/Kuwait, USA/Pakistan, and USA/Vietnam.

In contrast, the Gumbel copula, which is the best fit for USA/Mauritius, USA/Morocco and USA/Sri Lanka, depicts the asymmetry in co-movements of these pairs, indicating upper tail dependence between the USA and each frontier market. In order to understand why the Gumbel copula was chosen for these markets, we looked for days in which frontier markets and the USA 
registered simultaneous relevant increases. We searched the financial news looking for possible causes affecting the behavior of such stock markets in these days, ${ }^{6}$ and concluded that an unexpected improvement in USA stock market performance may have increased external investors' confidence.

The mixed Clayton-Gumbel-Frank (CGF) copula is selected solely for the pair USA/Argentina, depicting an asymmetric joint distribution. The weight assigned to the Clayton portion (0.4379) is higher than those of the Gumbel (0.2865) and Frank (0.2756) portions. The asymptotic tail coefficients $\lambda_{\mathrm{U}}=0.141$ and $\lambda_{\mathrm{L}}=0.107$ suggest that the markets of the USA and Argentina moved in tandem in both ups and downs.

The Clayton copula is chosen for the pairs USA/Estonia, USA/Jordan, USA/Lebanon and USA/Oman. The values of $\lambda_{\mathrm{L}}$ confirm that the USA and these frontier markets are more likely to crash than to boom together.

As referred above, although dependence coefficients from different copulas are not comparable, rank correlation measures, also directly obtained from the copulas, may be used to assess global dependence between pairs of markets. The values of the Kendal's $\tau$ increased from the calm to the crisis period in two cases: Croatia ( -0.0123 vs. 0.1441$)$ and Romania (0.0139 vs. 0.145$)$, suggesting that these two markets may have been affected by contagion from the subprime financial crisis. In the remaining markets, very weak increments in rank correlation values were registered.

In order to formally assess the existence of contagion, we computed the variation in the values of the Kendall's $\tau$ and the Spearman's $\rho$ form the pre-crisis to the crisis period (denoting it as $\Delta \tau$ and $\Delta \rho$ ) and assessed its statistical significance. For the bootstrap procedure, we constructed the probability function for $\Delta \tau$ and $\Delta \rho$ with $\mathrm{R}=1000$ repetitions. At each repetition, the values of $\Delta \tau$ and $\Delta \rho$ were extracted and stored for the calculation of the $p$-values, used to test the null hypotheses of no-contagion: $\mathrm{H} 0: \Delta \tau \leq 0, \mathrm{HO}: \Delta \rho \leq 0$.

Table 6 presents the results of the contagion tests. We rejected the null hypothesis of no contagion for Croatia and Romania at the 1\% significance level, confirming that contagion was stronger in European markets during the period covered by our study. All other assessed markets appear to have been relatively less exposed to the effects of the USA financial crisis. These results are in line with those of Su and Yip (2014) or Kiviaho et al. (2014), who reported that European frontier markets became more integrated with the USA in the financial crisis period.

Argentina, despite its relative geographical proximity, displays no significant signs of contagion from the subprime financial crisis. In 2008, a number of nationalizations were enacted and this may have somewhat isolated the country. ${ }^{7}$ Additionally, none of the Middle Eastern or African frontier markets displayed evidence of contagion. Most of these countries are major oil exporters, and therefore, more prone to suffer the impact of changes in crude oil prices (see e.g., Dutta et al. 2017; Ajmi et al. 2014). Moreover, evidence of contagion is not significant for Asian markets. Again, this supports previous assessments, for instance by Amin and Orlowski (2014), who reported that the frontier markets of Pakistan, Sri Lanka and Bangladesh remained decoupled from developed ones in periods of crisis, or by Beine et al. (2010), who concluded that less integrated countries have lower exposure to the negative impact of crises.

6 On 12 October 2008, European leaders met in Paris and announced the recapitalization of European banks and the implementation of plans to guarantee bank deposits for five years. They also announced the funding of rescue plans and an increase in short-term credits. On 13 October 2008, stock markets worldwide improved. On 28 October 2008, in response to an anticipated cut on central banks' reference rates of interest, the Dow Jones industrial index increased $11 \%$, according to the New York Times. In October, the International Monetary Fund's announcement of a release of emergency aid loans (including to countries of the Western Europe) reverberated back to the USA, as many affected countries were USA trading partners. We also found news of unexpected good performance for the Dow Jones industrial index on 13 November 2008.

7 The financial crisis had a strong negative impact on Argentinean pension funds, prompting the government to declare their nationalisation and transference to the National Social Security Administration. Guarantee and sustainability funds were established to manage the values involved (see e.g., Arza 2009). 
Table 6. Contagion Tests.

\begin{tabular}{cccccccccc}
\hline Country & $\boldsymbol{\Delta} \tau$ & \multicolumn{1}{c}{$p$ Value } & $\Delta \rho$ & $p$ Value & Country & $\Delta \tau$ & $p$ Value & $\Delta \rho$ & $p$ Value \\
\hline \multicolumn{7}{c}{ USA and Europe } \\
\hline Argentina & 0 & - & 0.0067 & 0.447 & Kenya & -0.0197 & 0.775 & -0.0296 & 0.775 \\
\hline Croatia & 0.1555 & $0.000^{* * *}$ & 0.1924 & $0.000^{* * *}$ & Mauritius & -0.03819 & 0.889 & -0.0570 & 0.888 \\
\hline Estonia & -0.0047 & 0.572 & -0.0071 & 0.572 & Morocco & 0.0189 & 0.279 & 0.0284 & 0.279 \\
\hline Romania & 0.1313 & $0.000^{* * *}$ & 0.1953 & $0.000^{* * *}$ & Nigeria & -0.0261 & 0.784 & -0.0392 & 0.145 \\
\hline Slovenia & 0.0305 & 0.21 & 0.0457 & 0.21 & Tunisia & 0.0352 & 0.165 & 0.0528 & 0.165 \\
\hline \multicolumn{7}{c}{ Middle East } \\
\hline Bahrain & -0.0208 & 0.722 & -0.0313 & 0.722 & Pakistan & -0.0161 & 0.703 & -0.0241 & 0.703 \\
\hline Jordan & 0.0138 & 0.329 & 0.0208 & 0.329 & Sri Lanka & 0.0241 & 0.21 & 0.0164 & 0.209 \\
\hline Kuwait & -0.000 & 0.755 & -0.000 & 0.755 & Vietnam & 0.000 & 0.515 & 0.008 & 0.441 \\
\hline Lebanon & 0.0133 & 0.299 & 0.0200 & 0.299 & - & - & - & - & - \\
\hline Oman & -0.0257 & 0.837 & -0.0385 & 0.652 & - & - & - & - & - \\
\hline
\end{tabular}

\section{Discussion}

Our investigation of contagion effects from the subprime financial crisis on 18 frontier markets was developed using copula models to examine dependence structures. Maximum likelihood procedures were employed to estimate the distribution function for each frontier market. Subsequently, eight copula models were considered and the best-fit for each of the pairs (one frontier market and the USA) was chosen with AIC values. The Kendall's $\tau$ and the Spearman's $\rho$ were used to assess the existence of contagion. The results of such tests indicated that Croatia and Romania exhibited statistically significant signs of having been affected by the subprime crisis. For the remaining markets, no statistically significant evidence of contagion was uncovered.

The analysis focused on frontier stock markets, characterized by their relatively small size, low liquidity, and small degree of foreign participation. Probably due to such features and to the specificities of their local economies, some with high exposure to commodities such as crude oil (many frontier markets are big oil exporters-Kuwait, for instance, controls around $6 \%$ of the world oil reserves and Nigeria earns more than $90 \%$ of its revenues by exporting oil), they were more protected from the effects of international financial shocks. Such countries have also been relatively less attractive to foreign investors, making their domestic financial returns less correlated with global markets. Investors' flight to safety in times of crisis, plus preference for alternative ways of financing economic activities in some of these countries may also explain the obtained results. ${ }^{8}$

Our study suggests that the large majority of frontier markets, and especially those not located in Europe, appear to be good options for international investors' diversification strategies, as they appear to be fairly insulated from major financial disturbances with origin in more developed markets. However, such potential benefits have to be pondered against problems such as low liquidity and high transaction costs. In order to improve the attractiveness of these markets for domestic and international investors, policymakers need to improve local stock market conditions and prevent irregularities while maintaining trading mechanisms capable of sustaining a level of protection against contagion from future crises. Moreover, they need to develop regulatory disclosure rules for all market participants who directly participate in such markets.

Author Contributions: Conceptualization, W.M., A.D., P.F. and I.V.; methodology, W.M., A.D. and I.V.; formal analysis, W.M., P.F., A.D. and I.V.; investigation, W.M., A.D., P.F. and I.V.; data curation, W.M., A.D. and I.V.

8 We thank an anonymous referee for having suggested this line of reasoning. 
writing—original draft preparation, W.M., A.D., P.F. and I.V; writing—review and editing, I.V., A.D. and P.F.; visualization, I.V., A.D. and P.F; supervision, I.V., A.D. and P.F.; funding acquisition, I.V., A.D. and P.F.

Funding: This paper is financed by National Funds of the FCT-Portuguese Foundation for Science and Technology within the project UID/ECO/04007/2019.

Conflicts of Interest: The authors declare no conflicts of interest.

\section{References}

Aas, Kjersti, Claudia Czado, Arnoldo Frigessi, and Henrik Bakken. 2009. Pair-copula constructions of multiple dependence. Insurance: Mathematics and Economics 44: 182-98. [CrossRef]

Ajmi, Ahdi Noomen, Ghassen El-Montasser, Shawkat Hammoudeh, and Duc Khuong Nguyen. 2014. Oil prices and MENA stock markets: New evidence from nonlinear and asymmetric causalities during and after the crisis period. Applied Economics 46: 2167-77. [CrossRef]

Aloui, Riadh, Mohamed Safouane Ben Aïssa, and Duc Khuong Nguyen. 2011. Global financial crisis, extreme interdependences, and contagion effects: The role of economic structure? Journal of Banking E Finance 35: 130-41.

Amin, Abu, and Lucjan Orlowski. 2014. Returns, Volatilities, and Correlations Across Mature, Regional, and Frontier Markets: Evidence from South Asia. Emerging Markets Finance and Trade 50: 5-27. [CrossRef]

Arza, Camila. 2009. Back to the State: Pension fund nationalization in Argentina. Documento de Trabajo Working Paper No. 72. Buenos Aires: Centro Interdisciplinario para el Estudio de Políticas Públicas.

Beine, Michel, Antonio Cosma, and Robert Vermeulen. 2010. The dark side of global integration: Increasing tail dependence. Journal of Banking \& Finance 34: 184-92.

Boubaker, Sabri, Jamel Jouini, and Amine Lahiani. 2016. Financial contagion between the US and selected developed and emerging countries: The case of the subprime crisis. The Quarterly Review of Economics and Finance 61: 14-28. [CrossRef]

Bouyé, Eric, Valdo Durrleman, Ashkan Nikeghbali, Gaël Riboulet, and Thierry Roncalli. 2000. Copulas for Finance-A Reading Guide and Some Applications. Unpublished Manuscript. London: Financial Econometrics Research Centre, City University Business School.

Clayton, David G. 1978. A model for association in bivariate life tables and its application in epidemiological studies of familial tendency in chronic disease incidence. Biometrika 65: 141-51. [CrossRef]

Da Silva, Marcus Fernandes, Éder Johnson de Area Leão Pereira, Aloisio Machado da Silva Filho, Arleys Pereira Nunes de Castro, José Garcia Vivas Miranda, and Gilney Figueira Zebende. 2016. Quantifying the contagion effect of the 2008 financial crisis between the G7 countries (by GDP nominal). Physica A: Statistical Mechanics and its Applications 453: 1-8. [CrossRef]

Daugherty, Mary Schmid, and Thadavillil Jithendranathan. 2015. A study of linkages between frontier markets and the U.S. equity markets using multivariate GARCH and transfer entropy. Journal of Multinational Financial Management 32-33: 95-115. [CrossRef]

Demian, Calin-Vlad. 2011. Cointegration in Central and East European markets in light of EU accession. Journal of International Financial Markets, Institutions and Money 21: 144-55. [CrossRef]

Dewandaru, Ginanjar, Rumi Masih, and A. Mansur M. Masih. 2015. Why is no financial crisis a dress rehearsal for the next? Exploring contagious heterogeneities across major Asian stock markets. Physica A: Statistical Mechanics and Its Applications 419: 241-59. [CrossRef]

Dimitriou, Dimitrios, Dimitris Kenourgios, and Theodore Simos. 2013. Global financial crisis and emerging stock market contagion: A multivariate FIAPARCH-DCC approach. International Review of Financial Analysis 30: 46-56. [CrossRef]

Dutta, Anupam, Jussi Nikkinen, and Timo Rothovius. 2017. Impact of oil price uncertainty on Middle East and African stock markets. Energy 123: 189-97. [CrossRef]

Embrechts, Paul, Alexander McNeil, and Daniel Straumann. 2002. Correlation and dependence in risk management: properties and pitfalls. Risk Management: Value at Risk and Beyond 1: 176-223.

Embrechts, Paul, Filip Lindskog, and Alexander McNeil. 2003. Modelling dependence with copulas and applications to risk management. In Handbook of Heavy Tailed Distributions in Finance. Edited by Svetlozar Rachev. Amsterdam: Elsevier, pp. 331-85. 
Forbes, Kristin J., and Roberto Rigobon. 2002. No contagion, only interdependence: measuring stock market co-movements. The Journal of Finance 57: 2223-61. [CrossRef]

Frank, Maurice J. 1979. On the simultaneous associativity of $\mathrm{F}(\mathrm{x}, \mathrm{y})$ and $\mathrm{x}+\mathrm{y}-\mathrm{F}(\mathrm{x}, \mathrm{y})$. Aequationes Mathematicae 19: 94-226. [CrossRef]

Fry, Renée, Vance L. Martin, and Chrismin Tang. 2010. A New Class of Tests of Contagion with Applications. Journal of Business \& Economic Statistics 28: 423-37.

Gallegati, Marco. 2012. A wavelet-based approach to test for financial market contagion. Computational Statistics $\mathcal{E}$ Data Analysis 56: 3491-97.

Guedes, Everaldo, Andreia Dionisio, P. J. Ferreira, and G. F. Zebende. 2017. DCCA cross-correlation in blue-chips companies: A view of the 2008 financial crisis in the Eurozone. Physica A: Statistical Mechanics and Its Applications 479: 38-47. [CrossRef]

Gumbel, Emil Julius. 1960. Distributions des valeurs extrêmes en plusieurs dimensions. Publications de l'Institut de Statistique de l'Université de Paris 9: 171-73.

Horta, Paulo. 2013. Contagion effects in the European NYSE Euro next stock markets in the context of the 2010 sovereign debt crisis. Investment Management and Financial Innovations 10: 114-24.

Horta, Paulo, Carlos Mendes, and Isabel Vieira. 2010. Contagion effects of the subprime crisis in the European NYSE Euronext markets. Portuguese Economic Journal 9: 115-40. [CrossRef]

Horta, Paulo, Sérgio Lagoa, and Luis Martins. 2014. The impact of the 2008 and 2010 financial crises on the Hurst exponents of international stock markets: Implications for efficiency and contagion. International Review of Financial Analysis 35: 140-53. [CrossRef]

$\mathrm{Hu}$, Ling. 2006. Dependence patterns across financial markets: A mixed copula approach. Applied Financial Economics 16: 717-29. [CrossRef]

$\mathrm{Hu}$, Jian. 2010. Dependence structures in Chinese and US financial markets: A time-varying conditional copula approach. Applied Financial Economics 20: 561-83. [CrossRef]

Khan, Saleheen, and Kwang Woo Ken Park. 2009. Contagion in the stock markets: The Asian financial crisis revisited. Journal of Asian Economics 20: 561-69. [CrossRef]

Kiviaho, Jarno, Jussi Nikkinen, Vanja Piljak, and Timo Rothovius. 2014. The Co-movement Dynamics of European Frontier Stock Markets. European Financial Management 20: 574-95. [CrossRef]

Kole, Erik, Kees Koedijk, and Marno Verbeek. 2007. Selecting copulas for risk management. Journal of Banking $\mathcal{E}$ Finance 31: 2405-23.

Lee, Lung-Fei. 1983. Generalized econometric models with selectivity. Econometrica: Journal of the Econometric Society 51: 507-12. [CrossRef]

Li, David X. 2000. On default correlation: A copula function approach. Journal of Fixed Income 9: 43-54. [CrossRef]

Longin, Francois, and Bruno Solnik. 2001. Extreme correlation of international equity markets. Journal of Finance 56: 649-76. [CrossRef]

Mashal, Roy, and Assaf Zeevi. 2002. Beyond Correlation: Extreme Co-Movements between Financial Assets. Technical Report. New York: Columbia Business School.

McLeish, Donald L., and Christopher G. Small. 1988. The Theory and Applications of Statistical Inference Functions. Lecture Notes in Statistics. Berlin: Springer, p. 44.

Mensi, Walid, Shawkat Hammoudeh, Duc Khuong Nguyen, and Sang Hoon Kang. 2016. Global financial crisis and spillover effects among the US and BRICS stock markets. International Review of Economics $\mathcal{E}$ Finance 42: 257-76.

Neaime, Simon. 2012. The global financial crisis, financial linkages and correlations in returns and volatilities in emerging MENA stock markets. Emerging Markets Review 13: 268-82. [CrossRef]

Nelsen, Roger. 2007. An Introduction to Copulas, 2nd ed. New York: Springer Science and Business Media.

Nikoloulopoulos, Aristidis K., Harry Joe, and Haijun Li. 2012. Vine copulas with asymmetric tail dependence and applications to financial return data. Computational Statistics \& Data Analysis 56: 3659-73.

Patton, Andrew J. 2006. Modelling asymmetric exchange rate dependence. International Economic Review 47: 527-56. [CrossRef]

Rodriguez, Juan Carlos. 2007. Measuring financial contagion: A copula approach. Journal of Empirical Finance 14: 401-23. [CrossRef]

Romero-Meza, Rafael, Claudio Bonilla, Hugo Benedetti, and Apostolos Serletis. 2015. Nonlinearities and financial contagion in Latin American stock markets. Economic Modeling 51: 653-56. [CrossRef] 
Schmidt, Thorsten. 2007. Coping with Copulas. Copulas-from Theory to Application in Finance. Torquay: Bloomberg Press, pp. 3-34.

Sklar, M. 1959. Fonctions de répartition à n dimensions et leurs marges. Publications de l'Institut de Statistique de l'Université de Paris 8: 229-31.

Su, Yuli, and Yewmun Yip. 2014. Contagion Effect of 2007 Financial Crisis on Emerging and Frontier Stock Markets. Journal of Accounting and Finance 14: 97-113.

Trivedi, Pravin K., and David M. Zimmer. 2005. Copula modeling: An introduction for practitioners. Foundations and Trends in Econometrics 1: 1-111. [CrossRef]

Xu, Qing, and Xiao-Ming Li. 2009. Estimation of dynamic asymmetric tail dependencies: an empirical study on Asian developed futures markets. Applied Financial Economics 19: 273-90. [CrossRef]

2019 by the authors. Licensee MDPI, Basel, Switzerland. This article is an open access article distributed under the terms and conditions of the Creative Commons Attribution (CC BY) license (http://creativecommons.org/licenses/by/4.0/). 